DOI: https://doi.org/10.24867/08BE11Ivkovic

\title{
MAGNETSKO POLJE SIMETRIČNOG TROFAZNOG VODA, SASTAVLJENOG OD "U” SABIRNICA
}

\section{MAGNETIC FIELD PRODUCED BY SYMMETRIC THREE PHASE SYSTEM CONTAINING „U“ SHAPED BUSBARS}

\author{
Jadranka Ivković, Karolina Kasaš-Lažetić, Fakultet tehničkih nauka, Novi Sad
}

\section{Oblast - ELEKTROTEHNIKA I RAČUNARSTVO}

Kratak sadržaj - U radu je izvršena analiza raspodjele intenziteta vektora magnetske indukcije $u$ okolini simetričnih trofaznih sabirnica u prisustvu neutralnog voda za četiri različita međusobna položaja „U” sabirnica i različite fazne stavove struja u njima. Dodatno je ispitan uticaj oklopljavanja sabirnica na raspodjelu magnetskog polja. Proračuni su izvršeni u programskom paketu „COMSOL Multiphysics”, koji radi na bazi metoda konačnih elemenata. Dobijeni rezultati su pokazali da promjena faznog stava jačina struja u sabirnicama kao i promjena položaja sabirnica dovodi do promjene raspodele magnetskog polja, a prisustvo oklopa smanjuje magnetsko polje izvan posmatranog sistema.

Ključne reči: Trofazne , $U$ ” sabirnice sa neutralnim provodnikom, Oklopljene sabirnice, Magnetsko polje, Metod konačnih elemenata (MKE)

Abstract - The paper analyzes the magnetic flux density distribution in the vicinity of symmetric three-phase busbars in the presence of a neutral line for four different intermediate positions of „U” busbars and different phase arrangement of currents. The effect of the busbars shielding on the distribution of the magnetic field is also examined. Calculations were performed in the software package "COMSOL Multiphysics" that is based on the finite element method. The obtained results showed that the current phase shift, as well as the position of the busbars change the magnetic field distribution and the enclosure reduces the magnetic field outside the observed system.

Keywords: Three phase „U” shaped busbars with neutral conductor, Shielded busbars, Magnetic field, Finite element method (FEM).

\section{UVOD}

Elektroenergetski sistem se sastoji od velikog broja dijelova koji su međusobno povezani i čine jednu složenu i funkcionalnu celinu. Sabirnice su jako važan dio svakog elektroenergetskog sistema i doprinose normalnom pogonu sklopnih postrojenja jer su svi vodovi povezani sa njima. Struje uspostavljene u energetskim simetričnim trofaznim sabirnicama stvaraju oko sebe niskofrekvencijsko (NF) magnetsko polje u kojima se mogu naći ljudi

\section{NAPOMENA:}

Ovaj rad proistekao je iz master rada čiji mentor je bila dr Karolina Kasaš-Lažetić, docent. i električni uređaji. Nastala magnetska polja mogu preko magnetskih sprega negativno da utiču na rad mnogih uređaja, tako da je praćenje nivoa magnetskog polja $\mathrm{u}$ okolini trofaznih sabirnica neophodno, radi očuvanja zdravlja ljudi i isprav-nog funkcionisanja uređaja koji se $u$ njima nalaze.

Sabirnice se najčešće izvode od neizolovanih bakarnih ili aluminijskih provodnika ili iz njihovih legura. Po obliku mogu biti pljosnati, okrugli ili savijeni u „U” profil. „U” profili su veoma pogodni za montažu u postrojenjima i imaju veoma dobre mehaničke karakteristike [1].

Zbog svega toga, cilj ovog rada jeste da se ispita uticaj, promene faznog stava struja u sabirnicama i uticaj prisustva oklopa oko sabirnica na raspodelu magnetskog polja u okolini trofaznih simetričnih „U” sabirnica u prisustvu neutralnog voda. Proračuni su izvršeni u programskom paketu COMSOL Multiphysics [2] posmatrajući dvodimenzionalan uprošćen model sistema. Rezultati su prikazani grafički, u vidu prostorne raspodele magnetskog polja kao i duž pravaca postavljenih paralelno sa osnovama sabirnica. Rezutati su ukazali na to da promenom faznih stavova struja u sabirnicama, može da se utiče na raspodelu magnetskog polja i da korištenje oklopa značajno redukuje magnetsko polje van oklopa.

\section{TEORIJSKA OSNOVA}

Elektromagnetsko polje koje stvaraju sabirnice su mrežne učestanosti (na ovim prostorima $50 \mathrm{~Hz}$ ) i kao takva spadaju u vremenski sporopromjenljiva polja. $\mathrm{Na}$ osnovu toga, analiza kako magnetske tako i električne komponente istog elektromagnetskog polja može da se vrši ponaosob, posmatranjem nezavisno vremenski sporopromjenljivog magnetskog polja i vremenski sporopromjenljivog elekričnog polja.

\subsection{Osnove proračuna}

Za opisivanje magnetskog polja, koristi se vektor magnetske indukcije, $\boldsymbol{B}$, dok se električno polje opisuje vektorom jačine električnog polja, $\boldsymbol{E}$. Određivanje ovih vektorskih veličina se najčešće vrši korišćenjem dva potencijala, električnog skalar potencijala $V$ i magnetskog vektor potencijala, $\boldsymbol{A}$. Vektor jačine električnog polja i vektor magnetske indukcije, izraženi preko potencijala mogu da se predstave preko relacija:

$$
\begin{aligned}
& \vec{E}=-\nabla V-\frac{\partial \vec{A}}{\partial t} \\
& \vec{B}=\nabla \vec{A}
\end{aligned}
$$

Pošto cijeli sistem može da se smatra linearnim, sa prostoperiodičnim strujama u sabirnicama, definisanje problema i njegovo rješavanje mogu da se izvrše u kom- 
pleksnom domenu. Dekartov pravougli koordinatni sistem je najpogodnije postaviti tako, da $z$ osa bude postavljena normalno na poprečni presjek sabirnica (Slika 1).

$\mathrm{U}$ tako izabranom koordinatnom sistemu, veličine od interesa, vektor gustine struje i magnetski vektor potencijal, imaju samo z komponentu, a mijenjaju se po koordinatama $x$ i $y$. Magnetski vektor potencijal se dobija kao rješenje parcijalne diferencijalne jednačine [3], [4]:

$$
\nabla \underline{\vec{A}}-j \omega \mu \sigma \underline{\vec{A}}=-\mu \underline{\vec{J}} .
$$

U Dekartovom koordinatnom sistemu, jednačina prelazi u skalarni oblik,

$$
\frac{\partial^{2} \underline{A}_{z}}{\partial x^{2}}+\frac{\partial^{2} \underline{A}_{z}}{\partial y^{2}}-j \omega \mu \sigma \underline{A}_{z}=-\mu \underline{J}_{z} .
$$

Za dobijanje partikularnog rješenja ove diferencijalne jednačine, neophodno je postaviti granične uslove. U prikazanom dvodimenzionalnom sistemu, intenzitet vektora elektromagnetskog polja opada sa rastojanjem od sistema, tako da se kao granični uslov usvaja da je magnetski vektor potencijal jednak nuli van zamišljenog kružnog prostora, čije su dimenzije mnogo veće od linearnih dimenzija poprečnog presjeka analiziranog sistema.

Usled indukovanog električnog polja, u provodnicima se uspostavlja i indukovana komponenta struje, $\underline{J}_{\text {indz }}$, tako da u provodniku postoji struja ukupne gustine

$$
\underline{J}_{u k z}=\underline{J}_{z}+\underline{J}_{\text {ind } z}(x, y) .
$$

Indukovane struje nastaju usled istovremenog dejstva površinskog efekta i efekta blizine, i dovode do neravnomjerne strujne raspodele u sabirnicama a samim tim utiču i na raspodelu magnetskog polja u sabirnicama i njihovoj okolini.

\section{MODEL}

Da bi se izvršila analiza raspodjele intenziteta vektora magnetske indukcije u okolini simetričnih trofaznih „U” sabirnica sa neutralnim vodom, u razmatranje je uzet sistem sastavljen od „U6” sabirnica, čije su standardizovane dimenzije prikazane u tabeli 1 , prema oznakama datih na slici 1 [5].

Tabela 1. Dimenzije standardizovanih "U6" sabirnica

\begin{tabular}{|c|c|c|c|c|c|}
\hline $\begin{array}{l}\text { Tip } \\
\text { sabirnice }\end{array}$ & $a[\mathrm{~mm}]$ & $b[\mathrm{~mm}]$ & $s[\mathrm{~mm}]$ & $d_{l}[\mathrm{~mm}]$ & $S\left[\mathrm{~mm}^{2}\right]$ \\
\hline $\mathrm{U6}$ & 60 & 30,0 & 4 & 25 & 448 \\
\hline
\end{tabular}

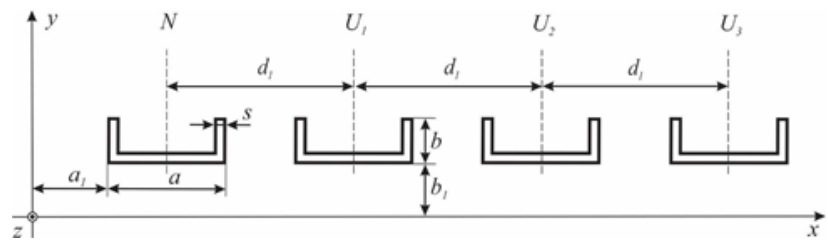

Slika 1. Raspored i dimenzije neoklopjenih „U6” sabirnica sa neutralnim vodom

Oznake $N, U 1, U 2$ i $U 3$ odgovaraju neutralnom vodu i sabirnicama prve, druge i treće faze respektivno. Rastojanje neutralne sabirnice do $y$ ose iznosi $a_{1}=35 \mathrm{~mm}$, dok su sve sabirnice na podjednakom rastojanju od $x$ ose, $b_{1}=45 \mathrm{~mm}$. Debljina oklopa iznosi $t=3 \mathrm{~mm}$. Izgled oklopljene sabirnice prikazan je na slici 2 .

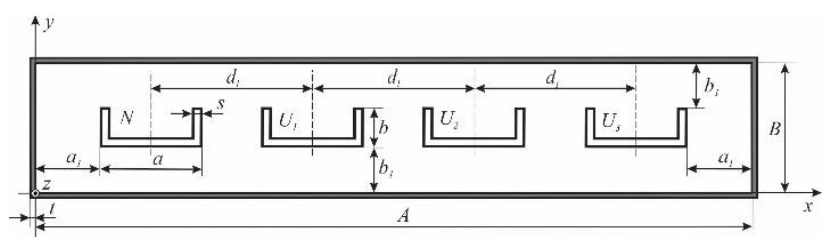

Slika 2. Raspored i dimenzije oklopljenih „U6” sabirnica sa neutralnim vodom

Problem je rešavan korišćenjem programskog paketa COMSOL Multhiphysics i pripadajućeg AC/DC modula. Postupak modelovanja prati određen šablon; postoji hronološki redoslijed koraka koje treba ispratiti. Prvo treba da se definiše prostor u kojem će se izvršiti analiza, a zatim modul koji pokriva fizičke karakteristike sistema. Za posmatran model to je 2D, Magnetic Fields (mf) Frequency Domain simulacija. Kada je izabran odgovarajući modul i tip simulacije, prvo treba da se definiše geometrija sistema. Nakon toga se dijelovima sistema pridružuju njihove elektromagnetske karakteristike i definišu sve ulazne veličine od interesa. U narednom koraku se postavljaju granični uslovi, a nakon toga se definiše mreža konačnih elemenata i rješava problem. Program izračunava raspodjelu magnetskog vektor potencijala, pomoću kojeg se zatim mogu odrediti ostale veličine od interesa. $\mathrm{U}$ posmatranom modelu to je bila raspodjela intenziteta vektora magnetske indukcije unutar i u okolini sabirnica.

$\mathrm{U}$ radu su posmatrane sabirnice načinjene od bakra. Specifična provodnost bakra je uzeta iz biblioteke paketa, $i$ iznosi $\sigma_{\mathrm{Cu}}=5,998 \mathrm{e} 7 \mathrm{~S} / \mathrm{m}$. Pošto se $u$ ovom modelu sabirnice nalaze u vazduhu, električne i magnetske karakteristike okruženja su podešene na odgovarajuće vrijednosti $\left(\varepsilon_{\mathrm{r} 0}=1, \mu_{\mathrm{r} 0}=1, \sigma_{0}=0\right)$. Cjelokupna posmatrana oblast je ograničena kružnim "oklopom” poluprečnika $R_{\mathrm{gr}}=2 \mathrm{~m}$, i debljine $d=50 \mathrm{~mm}$ u skladu sa opcijom definisanja domena "beskonačnih elemenata", pomoću kojeg se beskonačan domen modeluje oblašću konačnih dimenzija.

Oklop koji se u nekim delovima ispitivanja postavlja oko sabirnica je u ovom primjeru od aluminijuma i njegova specifična provodnost je takođe uzeta iz biblioteke paketa, $\sigma_{\mathrm{Al}}=3,771 \mathrm{e} 7 \mathrm{~S} / \mathrm{m}$. Uloga oklopa je da smanji magnetsko polje izvan njega u oblasti od interesa.

U posmatranom modelu, analiza je izvršena pretpostavljajući da je trofazni sistem simetričan, znači da su efektivne vrednosti jačina struja u sve tri sabirnice istog intenziteta, jednake nominalnoj jačini struje u posmatranim sabirnicama [5] i istog su smjera. Strujno opterećenje faznih provodnika je, u skladu sa tim, definisano kao

$$
\begin{aligned}
& \underline{I}_{1}=I_{1} e^{j 0^{\circ}}[k A], \\
& \underline{I}_{2}=I_{1} e^{-j 120}[k A], \\
& \underline{I}_{3}=I_{1} e^{-j 240^{\circ}}[k A] .
\end{aligned}
$$

Kompleksna vrijednost jačine struje u neutralnom provodniku simetričnog sistema iznosi $\underline{I}_{\mathrm{N}}=I_{1}+\underline{I}_{2}+\underline{I}_{3}=0$. Sabirnice su posmatrane da su od neobojenog bakra.

Pri izgradnji mreže konačnih elemenata, formirna je adaptivna mreža, koja je gušća u pojedinim oblastima sistema (u provodniku, u oklopu, duž pravaca proračuna), 
a rjeđa dalje od sabirnica unutar ostatka sistema. Gušća mreža se formira $u$ domenima gdje se očekuje veća promjena veličina od interesa. Izgled formirane mreže konačnih elemenata je prikazana na slici 3.

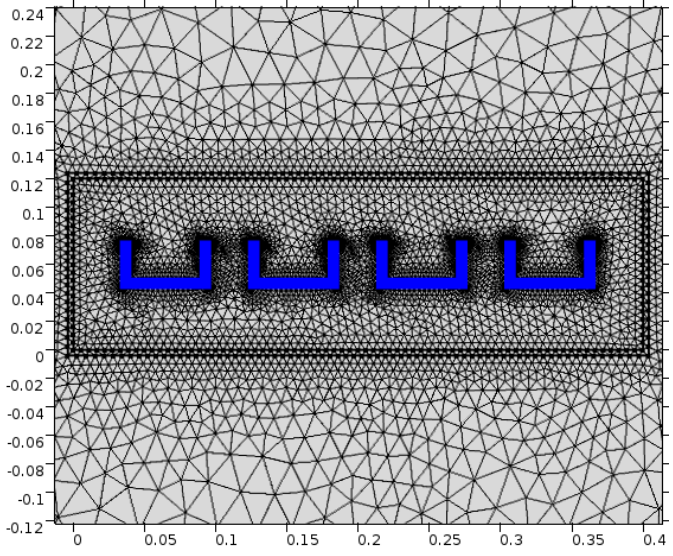

Slika 3. Dio modela sa formiranom mrežom

\section{REZULTATI}

$\mathrm{U}$ radu je izvršena analiza raspodjele magnetskog polja $\mathrm{u}$ okolini neoklopljenih i oklopljenih "U6" sabirnica.

Prvo je posmatran neoklopljen simetričan trofazni sistem " $U$ " sabirnica i ispitan je uticaj promjene faza na raspodjelu intenziteta vektora magnetske indukcije. Na slikama 4 i 5 predstavljena je prostorna raspodjela intenziteta vektora magnetske indukcije kroz poprečni presjek neoklopljenih provodnika "U" profila u zavisnosti od faznog stava struja u provodnicima sistema.

Posmatranjem uticaja promjene svih šest različitih faznih stavova struja u sabirnicama na raspodjelu intenziteta vektora magnetske indukcije, utvrđeno je, da promjena faza utiče na raspodjelu magnetskog polja. Analize su pokazale, da po tri fazna rasporeda daju istu raspodjelu intenziteta vektora magnetske indukcije: $123=231=312 \mathrm{i}$ $132=213=321$.

Upoređujući sike 4 i 5 može da se zapazi da se oblast najjačeg magnetskog polja javlja između faznih sabirnica, pod uticajem neravnomjerne raspodjele struja usljed površinskog efekta i efekta blizine [6]. Uočava se da najveće vrijednosti intenziteta vektora magnetske indukcije nastaju blizu uglova "U" sabirnica koji su okrenuti jedni prema drugima i te vrijednosti opadaju sa udaljavanjem od njih. U oblasti oko neutralnog voda, praktično nema magnetskog polja.

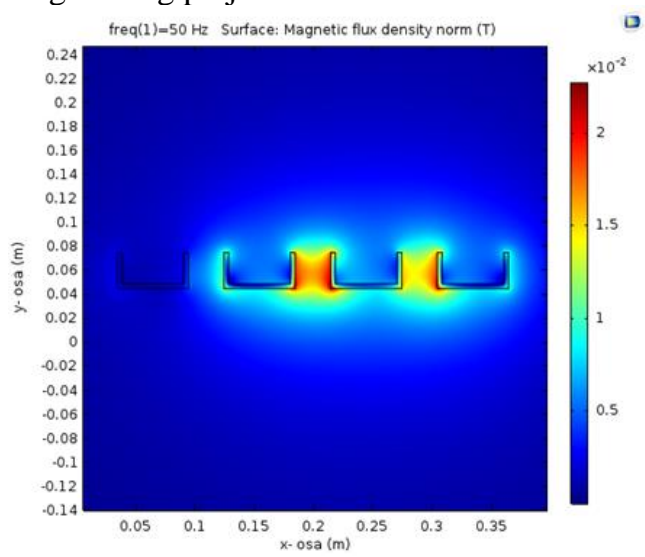

Slika 4. Prostorna raspodjela intenziteta vektora magnetske indukcije za raspored faza 123, 231, 312

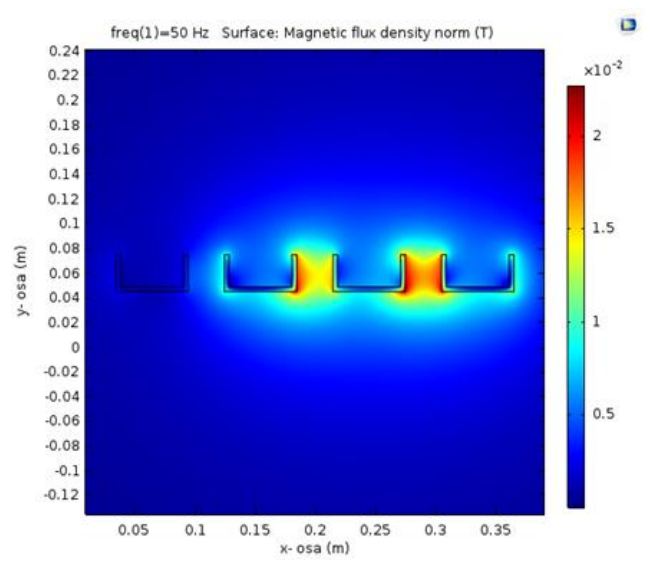

Slika 5. Raspodjela intenziteta vektora magnetske indukcije za raspored faza $132=213=321$

Posmatrajući slike 4 i 5 se vidi, takođe, da se oblast najjačeg polja preselio sa pozicije između prve i druge fazne sabirnice za prvu grupu faznih stavova struja, u oblast između druge i treće sabirnice, pri promeni faznih stavova struja na vrednosti druge grupe.

U nastavku analize, detaljnije je ispitana raspodjela intenziteta vektora magnetske indukcije u oblasti ispod i iznad sabirnica. Na slici 6 prikazana je raspodjela intenziteta vektora magnetske indukcije za raspored faza 123=231= 312 , duž pravaca koji prolaze kroz vazduh, ispod i iznad sabirnica, paralelno sa $x$ osom, pri čemu je, donja ivica sabirnica na visini $y=b_{1}=45 \mathrm{~mm}$. Pomoćne vertikalne linije na slici 6 označavaju položaj vertikalnih delova sabirnica, radi lakše analize dobijenih rezultata.

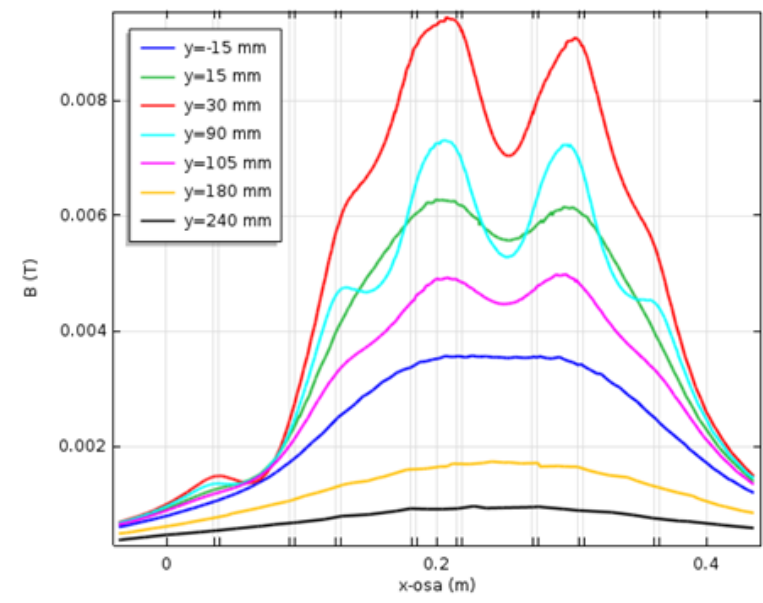

Slika 6. Raspodjela intenziteta vektora magnetske indukcije za raspored faza 123, 231, 312

Sa slike 6 se vidi da je raspodjela intenziteta vektora magnetske indukcije u vazduhu najveća ispod sabirnica $(y=30 \mathrm{~mm})$, sa izrazitim maksimumom između prve i druge fazne sabirnice i nešto manjim maksimumom između druge i treće fazne sabirnice, a da se smanjuje se udaljavanjem od njih.

Nakon ispitivanja raspodjele intenziteta vektora magnetske indukcije u okolini neoklopljenih simetričnih trofaznih sabirnica sa neutralnim vodom, izvršena je analiza uticaja oklopa na raspodjelu intenziteta vektora magnetske indukcije u okolini sabirnica. Na slici 7 prikazana je prostorna raspodjela intenziteta vektora magnetske indukcije $u$ okolini oklopljenih trofaznih sabirnica, za raspored faznih 
struja $123=231=312$, nakon što su sabirnice postavljene $u$ oklop od aluminijuma.

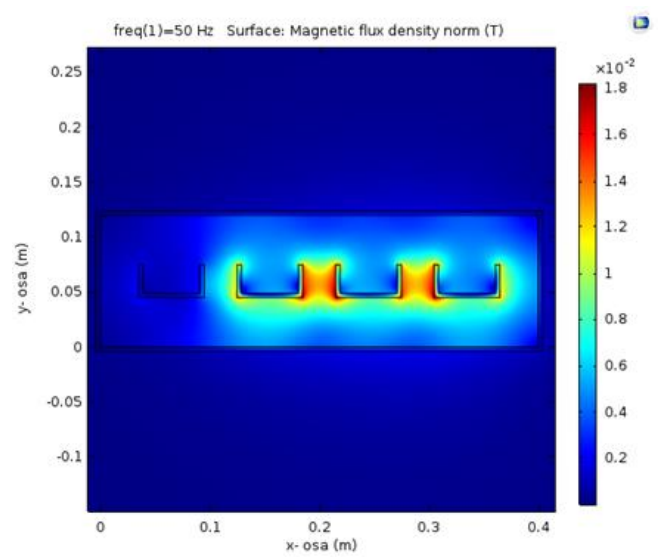

Slika 7. Prostorna raspodjela intenziteta vektora magnetske indukcije oklopljenih sabirnica za raspored faza 123, 231, 312

Upoređujući slike 4 i 7, može da se zaključi da je prostorna raspodela intenziteta vektora magnetske indukcije unutar oklopa izmenjena u odnosu na stanje pre oklopljavanja i da je u oblasti van oklopa intenzitet vektora magnetske indukcije mnogo manji nego pre oklopljavanja. $\mathrm{Na}$ slici 8 prikazani su rezultati dobijeni duž istih horizontalnih linija kao u slučaju neoklopljenog sistema sabirnica.

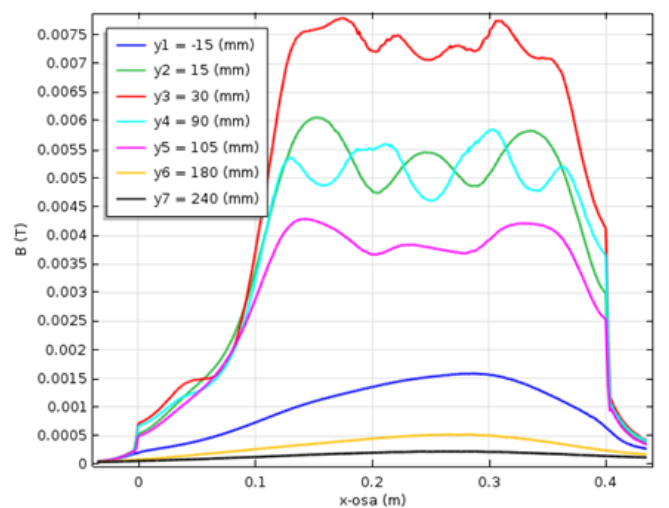

Slika 8. Raspodjela intenziteta vektora magnetske indukcije oklopljenih sabirnica za raspored faza 123, 231, 312

Sa slike 8 može odmah da se primjeti, da prisustvo oklopa skokovito smanjuje intenzitet vektora magnetske indukcije sa bočnih strana oklopa. Nagli pad intenziteta vektora magnetske indukcije iznad i ispod oklopa je takođe vidan $\mathrm{u}$ odnosu na neoklopljene sabirnice. Dovoljno je posmatrati vrednosti intenziteta vektora magnetske indukcije duž linije $y=-15 \mathrm{~mm}$ koja je najbliža donjoj strani oklopa, da bi se videlo smanjenje intenziteta vektora magnetske indukcije izvan oklopa. Indukovane struje u oklopu dovode do smanjenja intenziteta vektora magnetske indukcije izvan oklopa ali i do njegovog porasta unutar oklopa. Posmatrajući liniju $y=30 \mathrm{~mm}$ koja je najbliža donjoj strani oklopa, uočava se da su se nakon oklopljavanja maksimalne vrednosti intenziteta vektora magnetske indukcije smanjile, ali je srednja vrednost najvjerovatnije porasla. Taj pravac je najdalji od oklopa a najbliži sabirnicama, što znači da je uticaj struja u sabirnicama veći od uticaja struja indukovanih u oklopu.
Pomoću prikazanih grafika je pokazano, da prisustvo oklopa smanjuje intenzitet vektora magnetske indukcije u oblasti van oklopa i da po potrebi oklopljavanje može da se pimjeni u cilju zaštite prostora oko sabirnica od neželjenog dejstva magnetskog polja sabirnica.

\section{ZAKLJUČAK}

Sabirnice su neizostavni dio distributivnih sistema električne energije, kao i pogona većih snaga, tako da je poznavanje parametara sabirnica od velikog značaja za njihov adekvatan izbor.

U okviru rada je izvršen proračun raspodjele intenziteta vektora magnetske indukcije u okolini simetričnih trofaznih "U" sabirnica sa neutralnim provodnikom pri različitim faznim stavovima struja posmatrani bez oklopa i sa oklopom.

$\mathrm{U}$ radu je pokazano, da promena faznog stava struja $\mathrm{u}$ sabirnicama, menja raspodelu magnetskog polja, dok prisustvo oklopa značajno smanjuje intenzitet vektora magnetske indukcije izvan oklopa (na vrijednosti ispod $40 \%$ njene prvobitne vrijednosti). Time se pokazalo da se upotrebom oklopa može zaštititi prostor oko sabirnica od neželjenog dejstva magnetskog polja sabirnica.

Proračuni su izvršeni pomoću programskog paketa COMSOL Multiphysics. Izvršene analize su pokazale da se dati programski paket uspešno može primjeniti za rješavanje problema praktične, energetske elektromagnetike.

\section{LITERATURA}

[1] J. Nahman, V. Mijailović, „Razvodna postrojenja”, Akademska misao, Elektrotehnički fakultet, Beograd, 2005.

[2] COMSOL Muliphysics, documentation, 2016.

[3] B. D. Popović, ,Elektromagnetika”, Građevinska knjiga, Beograd, 2000.

[4] M. Stojaković, ,Matematička analiza 2“-drugi deo, 2. Izdanje, Fakultet tehničkih nauka Novi Sad, Novi Sad, 2007.

[5] LJ. Gerić, "Razvodna postrojenja-zbirka zadataka, drugo izdanje", Novi Sad, Fakultet tehničkih nauka, 2006.

[6] Jadranka Ivković, “Određivanje frekvencijski zavisne strujne raspodele u "U” sabirnici", diplomski rad, FTN Novi Sad, 2017.

\section{Kratka biografija:}

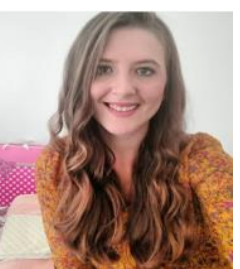

Jadranka Ivković rođena je 1993. godine u Trebinju. Master rad na Fakultetu tehničkih nauka iz oblasti Elektrotehnika i računarstvo - Energetska elektronika i električne mašine je odbranila 2019.god.

kontakt: jadrankajacaivkovic@yaoo.com

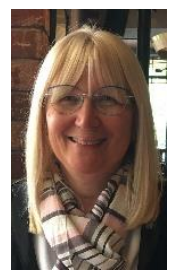

Karolina Kasaš-Lažetić, rođena je u Novom Sadu 1964. Doktorirala je na Fakultetu tehničkih nauka iz oblasti Elektrotehnike i računarstva. Oblast interesovanja je primenjena elektromagnetika. 